\title{
Nodulation Competitiveness of Ensifer meliloti Alfalfa Nodule Isolates and Their Potential for Application as Inoculants
}

\author{
MONIKA MAREK-KOZACZUK ${ }^{1 *}$, JERZY WIELBO ${ }^{1}$, ANNA PAWLIK $^{2}$ and ANNA SKORUPSKA ${ }^{1}$ \\ ${ }^{1}$ Department of Genetics and Microbiology, University of M. Curie-Skłodowska, Lublin, Poland \\ ${ }^{2}$ Department of Biochemistry, University of M. Curie-Skłodowska, Lublin, Poland
}

Submitted 25 July 2014, revised 4 September 2014, accepted 2 November 2014

\begin{abstract}
Alfalfa (Medicago sativa) is a widely cultivated legume, which enters into nitrogen-fixing symbiosis with Ensifer (Sinorhizobium) spp. In this study, an autochthonous rhizobial population of Ensifer sp. occupying alfalfa nodules grown in arable soil was used as the basis for selection of potential inoculants. Alfalfa nodule isolates were identified as Ensifer meliloti by partial $16 \mathrm{~S}$ rDNA, recA, atpD and nodC nucleotide sequencing. The sampled isolates displayed different symbiotic performance and diversity in the number of plasmids and molecular weight. Isolates that were the most efficient in symbiotic nitrogen fixation were tagged with a constitutively expressed gusA gene carried by a stable plasmid vector PJBA21Tc and used in competition experiments in soil under greenhouse conditions. Two E. meliloti strains LU09 and LU12, which effectively competed with indigenous soil rhizobia, were selected. The metabolic profiles of these selected strains showed differences in the use of carbon and energy sources. In addition, the LU09 strain exhibited bacteriocin production and LU12 mineral phosphate solubilization, which are valuable traits for soil survival. These strains may be considered as potential biofertilizers for alfalfa cultivation.
\end{abstract}

Ke y wo rds: biofertilizers, biological nitrogen fixation, competition, Ensifer/Sinorhizobium, symbiotic efficiency

\section{Introduction}

Biological nitrogen fixation is a global process that enriches soil in reduced nitrogen available for plants. The most productive in nitrogen fixation are symbiotic systems i.e., legume crops with their bacterial microsymbionts, which may fix up to a few hundred $\mathrm{kg} \mathrm{N}$ per $10^{4} \mathrm{~m}^{2}$ per year, so they are very important elements of modern sustainable agriculture (Brockwell et al., 1995; Herridge et al., 2008). Early steps in the establishment of symbiosis include attachment of bacteria to root hairs, exchange of molecular signals (usually plant flavonoids and bacterial Nod factors) between rhizobia and the plant host, and induction of morphological changes in plant root tissues, which lead to formation of nodules on plant roots (Perret et al., 2000; Jones et al., 2007). In these organs, physiologically distinct bacteroids surrounded by plant-derived peribacteroid membranes fix dinitrogen into forms useable for plants. The sequential stages of symbiosis are controlled by a set of bacterial nod genes responsible for nodulation and niffix genes involved in nitrogen fixation, and several plant host specific genes (Masson-Boivin etal., 2009). The bacterial genes are clustered on the symbiotic plasmid
(pSym) or the chromosome in a region called a symbiotic island (Palacios and Newton, 2005).

A hallmark of rhizobium-plant symbioses is their high specificity, possibly being the evolutionary consequence of the high level of diversity of both rhizobia and legume species; e.g. Rhizobium leguminosarum bv. trifolii nodulates only clover (Trifolium), R. leguminosarum bv. viciae - peas (Pisum) and vetch (Vicia), R. etli - bean (Phaseolus) and Ensifer meliloti - alfalfa (Medicago), and sweet clover (Melilotus) (MartinezRomero and Caballero-Mellado, 1996). In some cases, the specificity of symbiosis may be disadvantageous, because legume plants become non-nodulated and nitrogen source-deprived when there are no specific microsymbionts in the rhizosphere. In such cases, the application of an efficient and competitive rhizobial biofertilizer is recommended for achieving satisfactory cultivation results (Brockwell et al., 1995).

The high level of genetic and physiological diversity of soil rhizobia has been described even within the same species or biovar (Laguerre et al., 1996; Wielbo et al., 2010a). In addition, rhizobial populations displaying genetic polymorphism differ in nitrogen fixation efficiencies, sensitivity to detrimental environmental

* Corresponding author: M. Marek-Kozaczuk, Department of Genetics and Microbiology, Institute of Microbiology and Biotechnology, University of M. Curie-Skłodowska, Lublin, Poland; e-mail: monika.kozaczuk@poczta.umcs.lublin.pl 
factors, or competitive nodulation ability (Depret et al., 2008). The population of soil rhizobia specific to the plant host is usually a mixture of genetically different strains. On the other hand, legume roots have several nodulation zones susceptible to rhizobial invasion (Calvert et al., 1984; Mathesius et al., 2000), so one plant can be nodulated by more than one strain (Wielbo et al., 2010b). The genetically diverse strains occupying one nodule may significantly differ in their ability to metabolize carbon and energy sources and $\mathrm{N}_{2}$ fixation efficiency (Simms and Taylor, 2002). Competition for nodulation of the host legume by resident rhizobial populations in soil represents a serious problem affecting the establishment of efficient nitrogen-fixing inoculants (Brockwell et al., 1995). In many cases, selected, highly effective rhizobial strains used as plant inoculants are less competitive than autochthonous strains, and are outnumbered by the soil population (Streeter, 1994). Taken together, there is a need for further screening of soil population to identify highly efficient and competitive rhizobia that might be used as inoculants for leguminous plants.

Medicago sativa is infected mostly and efficiently with E. meliloti and less frequently but efficiently, with E. medicae or Phyllobacterium sp. and Rhizobium sp. (Silva et al., 2007; Bromfield et al., 2010). According to published data, alfalfa (M. sativa) microsymbionts have been found as less numerous compared with other rhizobial species in Polish soils (Martyniuk et al., 2000; Martyniuk et al., 2005). Therefore, there is a demand for selection of Ensifer spp. from a particular environment to use them as potential inoculants to increase alfalfa crop productivity.

The aim of this work was to select E. meliloti strains exhibiting high efficiency in nitrogen fixation with a competitive ability for nodule occupancy in relation to autochthonous rhizobia under greenhouse conditions. Metabolic profiles of the sampled E. meliloti strains were characterized. Two selected E. meliloti strains may be considered as inoculants in alfalfa field cultivation in Poland.

\section{Experimental}

\section{Materials and Methods}

Bacterial strains. Ensifer spp. isolates derived from root nodules of alfalfa (Medicago sativa cv. Radius) grown in arable soil in the region of Lublin, Poland. Nodules were surface sterilized by immersion in $0.1 \%$ $\mathrm{HgCl}_{2}$ for $1 \mathrm{~min}$, rinsed with sterile distilled water, then treated with $70 \%$ ethanol for $1 \mathrm{~min}$, followed by extensive washing with sterile water. Suspensions from crushed nodules were grown and maintained in 79CA medium (Vincent, 1970). Rhizobia isolated from nodules were purified by successive isolation of single colonies grown on the same medium and used in further experiments.

The number of alfalfa microsymbionts in the soil was estimated by a most probable number plant infectivity test similar to described by Martyniuk etal., (2000). Briefly, seeds were surface sterilized and sown in plastic pots containing $600 \mathrm{~g}$ of washed and sterilized sand, once watered with $150 \mathrm{ml} \mathrm{N}$-free Fahraeus medium. Soil sample $(10 \mathrm{~g})$ was mixed with $90 \mathrm{ml}$ of sterile water, and after sedimentation of solid phase tenfold dilutions of liquid phase $\left(10^{-2}-10^{-6}\right)$ were prepared. $1 \mathrm{ml}$ aliquots of these dilutions were used for inoculation of pots with alfalfa seeds, and for each dilution three pots were prepared. After emergence of seedlings, plants were randomly thinned and five alfalfa plants were left in each pot. Plants were grown for six weeks, and then the presence of root nodules was examined. A pot was scored as "positive" when root nodule/nodules were present on any root in the pot and as "negative" when none of plants grown in one pot were nodulated. The number of alfalfa microsymbionts present in soil was estimated according to the number of pots containing nodulated plants for each dilution of soil extract and using special tables (Brockwell, 1982).

DNA analyses. Plasmid content of the isolates was analyzed by the method of Eckhardt (1978). Plasmid size estimation was performed using Bio-Profile V11.01 (Vilber-Lourmat, France) by comparison with R. leguminosarum bv. viciae 3841 standard plasmids (Young et al., 2006).

Genomic DNA of seven selected most efficient isolates was extracted from $5 \mathrm{ml}$ of 2-day cultures in liquid 79CA medium using method of Pitcher et al., 1989. The primers used for BOX-PCR, ERIC-PCR, amplification and sequencing the genes encoding $16 \mathrm{~S}$ rRNA, recA, atpD and nodC are described in Table I. BOXA-PCR and ERIC-PCR genomic fingerprints were obtained as described by Louws et al., 1994 and Versalovic et al., 1991. The sequences were aligned with those from GenBank using the MEGA5.05 software package (Tamura et al., 2011). The distances were calculated according to the Kimura's 2-parameters (Kimura, 1980). Phylogenetic trees were inferred using neighbor-joining method (NJ). Bootstrap analyses were calculated based on 1000 replications (Felsenstein, 1985). Chromosomal $16 \mathrm{~S}$ rRNA, $r e c A$, atpD and nodC gene sequences determined in this study have been deposited in the EMBL database, and the GenBank under following accession numbers: KJ652948 - KJ652952, EU182657 (16S rRNA), KJ847190 - KJ847195 (nodC), KM096990 - KM096993, KJ847188, KJ847189 (recA), KJ847196 - KJ847200, KJ825827 (atpD).

Symbiotic performance test of Ensifer meliloti nodule isolates in sterilized sand. Alfalfa seeds were 
Table I

Primers used in this study

\begin{tabular}{|c|c|c|c|c|c|}
\hline Gene & Primer & Sequence $5^{\prime}-3^{\prime}$ & $\begin{array}{l}\text { Annealing } \\
\text { temperature }\end{array}$ & $\begin{array}{c}\text { Amplicon } \\
\text { length (bp) }\end{array}$ & References \\
\hline \multirow{2}{*}{$\operatorname{atpD}$} & atpD294 & ATCGGCGAGCCGGTCGACGA & \multirow{2}{*}{$58^{\circ} \mathrm{C}$} & \multirow{2}{*}{460} & \multirow{2}{*}{ Gaunt et al. 2001} \\
\hline & atpD771 & GCCGACACTTCCGAACCNGCCTG & & & \\
\hline \multirow{2}{*}{ 16S rRNA } & fD1 & CCGAATTCGTCGACAACAGAGTTTGATCCTGGCTCAG & \multirow{2}{*}{$55^{\circ} \mathrm{C}$} & \multirow{2}{*}{1299} & \multirow{2}{*}{ Weisburg et al. 1991} \\
\hline & rD1 & CCCGGGATCCAAGCTTAAGGAGGTGATCCAGCC & & & \\
\hline \multirow{2}{*}{ recA } & recA6f & CGKCTSGTAGAGGAYAAATCGGTGGA & \multirow{2}{*}{$56^{\circ} \mathrm{C}$} & \multirow{2}{*}{533} & \multirow{2}{*}{ Aoki et al. 2010} \\
\hline & recA640r & ACATSACRCCGATCTTCATGC & & & \\
\hline \multirow{5}{*}{ nodC } & nodCmelF & TTCAATGAGGACCCAGGCATCCTCTC & \multirow{2}{*}{$56^{\circ} \mathrm{C}$} & \multirow{2}{*}{915} & \multirow{2}{*}{ This study } \\
\hline & nodCmelR & GCTTTCCCCCGCTGACTGGTAC & & & \\
\hline & BOX 1AR & CTCCGGCAAGGCGACGCTGAC & $53^{\circ} \mathrm{C}$ & & Louws et al. 1994 \\
\hline & ERIC 1R & ATGTAAGCTCCTGGGGATTCAC & \multirow{2}{*}{$52^{\circ} \mathrm{C}$} & & \multirow{2}{*}{ Versalovic et al. 1991} \\
\hline & ERIC 2 & AAGTAAGTGACTGGGGTGAGCG & & & \\
\hline
\end{tabular}

surface sterilized and sown in pots filled with $400 \mathrm{~g}$ washed, sterilized sand and supplemented with $100 \mathrm{ml}$ N-free Fahreus medium (Vincent, 1970). Individual 18 isolates were grown with shaking in 79CA medium for $48 \mathrm{~h}$ at $28^{\circ} \mathrm{C}$, centrifuged and the bacterial pellet was suspended in sterile water. $3 \mathrm{ml}$ of cell suspension $\left(\mathrm{OD}_{550} 0.1\right.$, approx. $10^{8}$ cells $\left.\mathrm{ml}^{-1}\right)$ was added to each pot. Plants (10 seedlings per pot, in triplicate) were grown in a greenhouse under natural light supplemented with artificial light $\left(14 \mathrm{~h}\right.$ day $/ 10 \mathrm{~h}$ night, at $\left.24 / 19^{\circ} \mathrm{C}\right)$ and were periodically watered with sterile water. After 6 weeks, the plants were harvested, weighted and root nodules were counted. All plants from one experimental group were collected, dried at $65^{\circ} \mathrm{C}$ for $48 \mathrm{~h}$, weighted and mean dry mass of shoots was calculated after dividing the whole mass of dried shoots by a number of plants. The six most efficient growth-promoting isolates (as assayed by weighing the green parts of plants) were chosen for further experiments (Table II).

Tagging of rhizobia with gusA gene. To study an ability to nodule occupancy and competitiveness, six most efficient in nitrogen fixation nodule isolates were tagged with a stable plasmid vector pJBA21Tc carrying a constitutively expressed gusA (Wielbo et al., 2007).

Table II

Symbiotic performance of alfalfa nodule isolates grown in sterile sand

\begin{tabular}{|l|c|c|c|c|}
\hline \multicolumn{1}{|c|}{ Isolate } & $\begin{array}{c}\text { Fresh mass } \\
\text { of shoots* } \\
(\mathrm{mg})\end{array}$ & $\begin{array}{c}\text { Dry mass } \\
\text { of shoots } \\
(\mathrm{mg})\end{array}$ & $\begin{array}{c}\text { Relative fresh mass } \\
\text { of shoots (uninoculated } \\
\text { control plant=1) }\end{array}$ & $\begin{array}{c}\text { Number } \\
\text { of nodules } \\
\text { per plant* }\end{array}$ \\
\hline LU02 & $186 \pm 26$ & 33 & 4.13 & $6.8 \pm 2.9$ \\
\hline LU04 & $202 \pm 39$ & 36 & 4.5 & $8.3 \pm 8.3$ \\
\hline LU05 & $165 \pm 27$ & 30 & 3.75 & $13.5 \pm 6.2$ \\
\hline LU06 & $182 \pm 24$ & 32 & 4.0 & $11.9 \pm 4.8$ \\
\hline LU07 & $161 \pm 36$ & 26 & 3.25 & $9.7 \pm 5.6$ \\
\hline LU08 & $217 \pm 18$ & 39 & 3.5 & $12.0 \pm 6.1$ \\
\hline LU09 & $216 \pm 62$ & 38 & 4.88 & $12.6 \pm 5.8$ \\
\hline LU10 & $200 \pm 27$ & 36 & 4.75 & $9.6 \pm 4.9$ \\
\hline LU11 & $194 \pm 35$ & 36 & 4.5 & $10.7 \pm 3.2$ \\
\hline LU12 & $116 \pm 45$ & 23 & 4.5 & $12.0 \pm 5.8$ \\
\hline LU15 & $134 \pm 21$ & 23 & 2.88 & $6.8 \pm 2.4$ \\
\hline LU17 & $175 \pm 30$ & 29 & 2.88 & $6.4 \pm 1.0$ \\
\hline $\begin{array}{l}\text { Uninoculated alfalfa grown on sand with Fahraeus } \\
\text { medium supplemented with 20 mM NH }{ }_{4} \text { Cl }\end{array}$ & $57 \pm 19$ & 8 & 3.63 & - \\
\hline $\begin{array}{l}\text { Uninoculated alfalfa grown on sand with N-free } \\
\text { Fahraeus medium }\end{array}$ & & 1.0 & - \\
\hline
\end{tabular}

* Values are mean of 30 plants. \pm standard deviation 
The pJBA21Tc plasmid was introduced into rhizobia by electroporation $(1800 \mathrm{~V}, 200 \Omega, 50 \mu \mathrm{F})$ as described previously. After electroporation, rhizobia were selected on 79CA agar medium supplemented with $10 \mu \mathrm{g} \mathrm{ml}^{-1}$ tetracycline and $50 \mu \mathrm{g} \mathrm{ml}^{-1} \mathrm{X}$-GlcA (5-bromo-4-chloro-3indolyl $\beta$-D-glucuronide) substrate for $\beta$-glucuronidase. Stability of plasmid pJBA21Tc in rhizobia was confirmed earlier (Wielbo and Skorupska, 2001).

E. meliloti competition assay in sterile $\mathrm{N}$-free medium. Alfalfa seeds were surface sterilized, germinated, and grown on Fahraeus agar medium slants (1 seedling/tube) (Vincent, 1970). 5-day-old seedlings were inoculated with a mixture $(1: 1 \mathrm{v} / \mathrm{v})$ of $g u s A$ marked and unmarked E. meliloti isolates. A $200 \mu \mathrm{l}$ cell suspension at an $\mathrm{OD}_{550} 0.1$ was added to each slant. Plants were cultured for 6 weeks, harvested and weighted. Alfalfa roots were stained for $\beta$-glucuronidase (Gus) activity in $50 \mathrm{mM}$ sodium phosphate buffer ( $\mathrm{pH} 7.2$ ) with $50 \mu \mathrm{g} \mathrm{ml}^{-1}$ 5-bromo-4-chloro-3-indolyl $\beta$-D-glucuronide (X-GlcA), $0.1 \mathrm{mM}$ EDTA, $0.38 \mathrm{mM}$ $\mathrm{K}_{3} \mathrm{Fe}(\mathrm{CN})_{6}$ and $0.38 \mathrm{mM} \mathrm{K}_{4} \mathrm{Fe}(\mathrm{CN})_{6}$ for about $1 \mathrm{~h}$ at room temperature (Wilson et al., 1995). The number of stained (blue) and unstained (white) nodules colonized by tagged and non-tagged strains were counted.

In experiment 1 , non-sterilized alfalfa seeds were soaked $15 \mathrm{~min}$ in a water suspension of respective E. meliloti isolate marked with pJBA21TcgusA $\left(\mathrm{OD}_{550} 0.1\right)$ and sown in the pots. Twenty alfalfa plants were grown per pot filled with $1500 \mathrm{~g}$ of non-sterile soil (N:P:K ratio: $0.16 \% \mathrm{w} / \mathrm{w} \mathrm{N}: 14.2 \mathrm{mg} \mathrm{P}_{2} \mathrm{O}_{5}: 12.8 \mathrm{mg} \mathrm{K}_{2} \mathrm{O}$ ).

In experiment 2, non-sterilized alfalfa seeds were sown in the pots with the same soil and inoculated with suspension of respective E. meliloti isolate tagged with pJBA21Tc gusA with defined increasing number of rhizobia, i.e. $10^{8}, 10^{9}$ or $10^{10}$ per pot. Alfalfa plants were grown in a greenhouse under natural light supplemented with artificial light $(14 \mathrm{~h}$ day/ $10 \mathrm{~h}$ night, at $24 / 19^{\circ} \mathrm{C}$ ) and were periodically watered with water. After 6 weeks, whole roots of alfalfa plants were harvested, washed with sterile water and stained for $\beta$-glucuronidase (Gus) activity. Competitive potential of the tested inoculants was estimated by comparing the number of blue nodules colonized by the introduced gusA-tagged strains with white nodules colonized by autochthonous strains.

Biolog phenotypic assay. To study metabolic activity of E. meliloti isolates Biolog GN2 MicroPlate ${ }^{\mathrm{TM}}$ (Gram Negative Identification Test Panel) (Biolog, Hayward, U.S.A.) was used. Briefly, rhizobia grown overnight at $28^{\circ} \mathrm{C}$ on $79 \mathrm{CA}$ agar medium were collected and washed twice with sterile water. Next, the pellet was diluted in water to an initial $\mathrm{OD}_{550}$ of 0.1 (approximately $10^{8}$ cells $\mathrm{ml}^{-1}$ ) and $150 \mu \mathrm{l}$ of the rhizobial suspension was inoculated into each of 95 wells of the GN2 microplate. The plates were incubated for $72 \mathrm{~h}$ at $28^{\circ} \mathrm{C}$ and colour development (absorbance at 590 and $750 \mathrm{~nm}$ ) in the wells was recorded using a Benchmark Plus microplate reader (Bio-Rad Laboratories, U.S.A.). The conversion of colourless tetrazolium violet to a purple-coloured compound meant a normal process of respiration (positive phenotype), whereas, when the phenotype was negative, the wells remained colourless. The optical density values of the Biolog microplate wells were corrected using background colour developed in the control well.

Solubilization of phosphates assays and bacteriocin production assay. E. meliloti strains were grown on $79 \mathrm{CA}$ medium supplemented with $5 \mathrm{~g} \mathrm{l}^{-1} \mathrm{Ca}_{3}\left(\mathrm{PO}_{4}\right)_{2}$ for $48 \mathrm{~h}$ at $28^{\circ} \mathrm{C}$ and diameter of cleared zones around bacterial colonies were measured. The width of cleared zones was assumed as proportional to the ability of rhizobia to solubilization of $\mathrm{Ca}_{3}\left(\mathrm{PO}_{4}\right)_{2}$. The ability to bacteriocin production was tested on two layer plates in 79 CA medium and Ensifer meliloti L5-30 was used as bacteriocin-sensitive indicator strain.

Data statistical analysis. Statistical analysis was carried out by the analysis of variance and Tukey test (significance level of $\mathrm{P}<0.05$ ) with STATISTICA for Windows software (StatSoft Inc., Tulsa, U.S.A.).

\section{Results}

Characteristics of the Ensifer sp. alfalfa nodule isolates. The number of microsymbiont population in soil originating from the local site of alfalfa (M. sativa) cultivation was estimated by a most probable number plant infectivity test in the growth pouches and calculated as $4.4 \times 10^{4}$ cells $\mathrm{g}^{-1}$, which allowed us to classify this soil as rich in these bacteria. Alfalfa microsymbionts were isolated from nodules of alfalfa plants grown in the soil. Eighteen randomly chosen Ensifer sp. nodule isolates were assayed for the content of plasmids in order to eliminate identical strains. On the basis of plasmid content screening, a very high level of diversity among the isolates was observed. Twelve of the 18 isolates had distinct profiles of plasmids and these were considered as different strains. Each of the twelve isolates possessed from 1 to 4 plasmids with molecular weight in the range from ca. $40 \mathrm{~kb}$ to above $1 \mathrm{Mb}$ : six of the twelve strains possessed a very large megaplasmid (approx. 1 Mb) (Fig. 1).

To select potential Ensifer sp. inoculants, twelve strains differing in the pattern of plasmids were tested for nodulation and capability of plant growth promotion on M. sativa grown in sterile sand supplemented with $\mathrm{N}$-free medium. The sampled isolates varied in the symbiotic activity, i.e. fresh and dry shoot mass and the number of nodules per plant (Table II). They promoted alfalfa growth measured by fresh mass of shoots in the range from 2.03 to 3.8 times, and dry mass from 


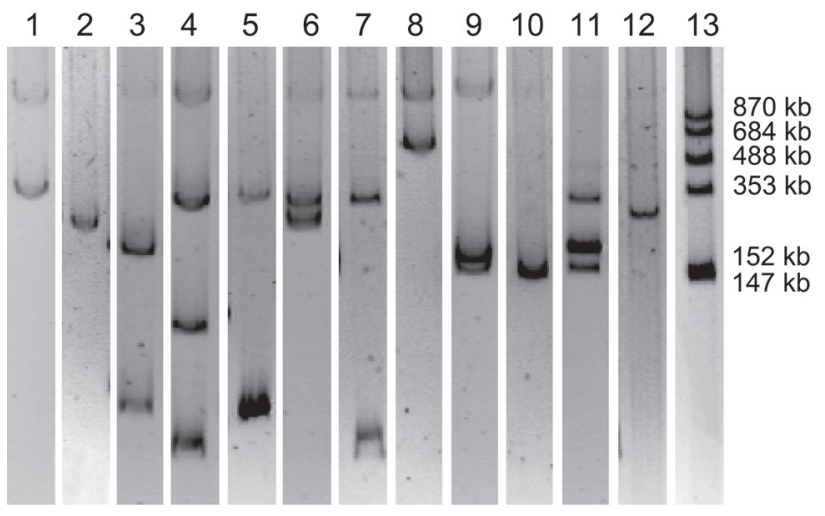

Fig. 1. Plasmid profile of the selected rhizobial strains isolated from alfalfa nodules. The plasmids were visualized by the Eckhardt method. Lanes 1 - 12, E. meliloti strains: LU02, LU04, LU05, LU06, LU07, LU08, LU09, LU10, LU11, LU12, LU15, LU17, respectively; lane 13 - plasmids of R. leguminosarum bv. viciae strain 3841 used as a molecular weight standard.

2.88 to 4.88 in relation to uninoculated control plants grown on sterile sand with $\mathrm{N}$-free medium. The growth of alfalfa inoculated with the selected isolates was also better than that of non-inoculated plants growing on sand with Fahreus medium supplemented with $20 \mathrm{mM}$ ammonium chloride. Six symbiotically most efficient strains (LU04, LU06, LU09, LU10, LU11, LU12) were chosen for further competition experiments.

Another parameter used to evaluate rhizobial efficiency is the number of nodules per plant; however, this value usually does not correlate with the level of nitrogen fixation. In our experiment, the most efficient isolates selected formed from 8.3 to 12.6 nodules per plant, which is almost two times more than the least efficient isolates (LU02, LU15, LU17) (Table II).

The genetic relationships between the six selected isolates were studied by generating genomic fingerprints using BOX-PCR and ERIC-PCR. Visual analyses of BOX- and ERIC- fingerprints showed similar patterns in more than a dozen bands of different intensities and indicated apparent relatedness among the isolates. In general, low differentiation of the isolates was observed with the use of these methods, despite substantial plasmid diversity in the various strains. Dendrogram obtained on the basis of two combined profiles showed LU10 and LU12 as most similar (90\%) and LU09 as the most diverse ( $68 \%$ similarity) strains (Fig. 2$)$.

Since $M$. sativa enters into symbiotic relationships with species from the Ensifer, Phyllobacterium and Rhizobium genera (Bromfield et al., 2010), the phylogenetic position of the six selected isolates was examined by partial sequencing of the $16 \mathrm{~S}$ rRNA gene (1299 bp). The $r r n$ sequences of the six isolates were identical to each other (100\%) and identical to several E. meliloti strains. To confirm the species identification, the atpD (460 bp), and recA (533 bp) housekeeping genes were sequenced and found to be identical (100\%) to E. meliloti type strains (data not shown).

The nod genes involved in Nod factor synthesis are localized in E. meliloti on the pSymA symbiotic plasmid (Barnett et al., 2001) and generally have different phylogenetic history than chromosomal core genes (Laguerre et al., 2003; Young et al., 2006). The nodC, a key gene for Nod factor synthesis, encoding N-acetyl-glucosaminyl transferase is located in E. meliloti on the pSymA plasmid. The nodC genes of 6 alfalfa isolates were PCR amplified, sequenced, and used for construction of the phylogram (Fig. 3). In nodC tree, 5 of the 6 isolates were located in a separate, closely related cluster together with E.kummerowiae CCBAU71714 and E.meliloti AK83, 2011, 1021. The LU11 nodC was more divergent but still 99\% identical to E. meliloti SM11 and 96\% identical to E. meliloti AK83 and other strains of this cluster. In conclusion, based on chromosomal $r r n, r e c A$, atpD and nodC plasmid gene sequences, the six alfalfa nodule isolates selected were identified as E. meliloti.
A

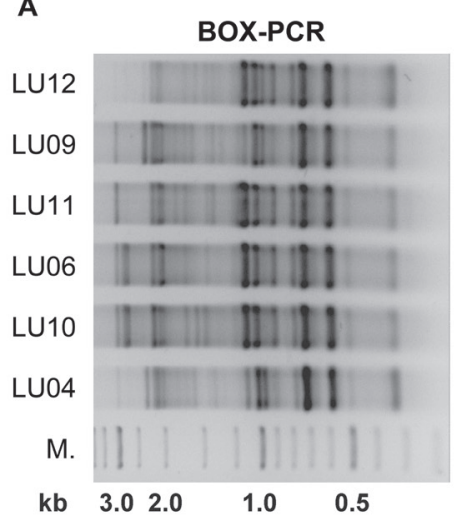

B

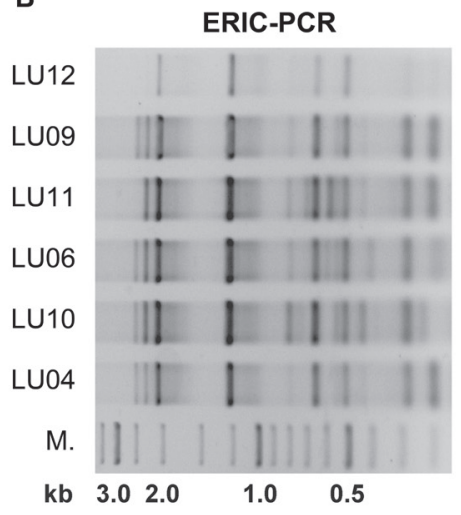

C

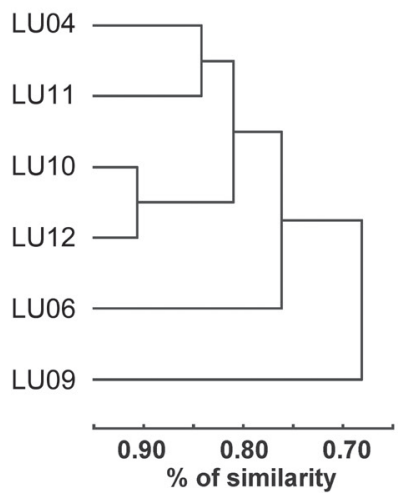

Fig. 2. A) BOX-PCR and B) ERIC-PCR fingerprint patterns from the genomic DNA of the microsymbionts isolates. The names of the isolates are shown on the left of the figures. $\mathrm{M}$ - the DNA molecular size marker in $\mathrm{kb}$.

C) Cluster analysis-based dendrogram (UPGMA method) constructed on the basis of combined BOX-and ERIC-PCR-generated genomic fingerprints showing diversity of the selected Ensifer sp. 


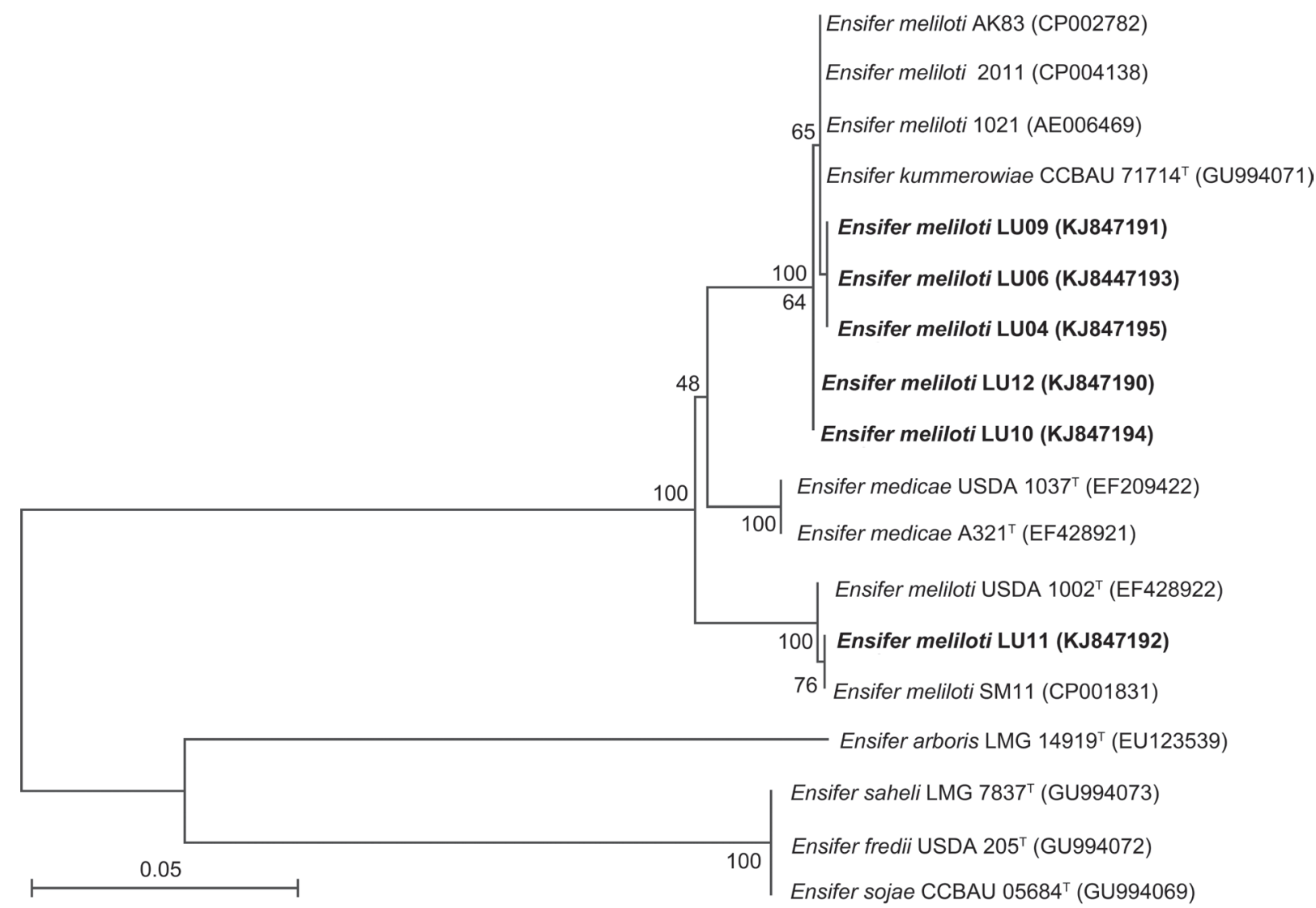

Fig. 3. Neighbor -joining (NJ) tree showing the phylogenetic relationship between Ensifer sp. isolates and related Ensifer species based on nodC gene sequences. Bootstrap values are given at the nodes. GenBank accession numbers are given in parentheses. Bar, nucleotide substitutions per nucleotide position.

Nodulation competitiveness of E. meliloti isolates. The ability to compete for host plant nodulation is a complex phenomenon and depends on genetic traits of microsymbionts and on soil and environmental factors (Triplett and Sadowsky, 1992). To study the nodulation competitiveness of the isolates and differentiate the sampled isolates from autochthonous rhizobia, the most efficient E. meliloti isolates (6 strains) were marked with gusA carried on a stable pJBA21Tc plasmid. First, a potential impact of gusA-tagging on the strain ability of nodule colonization was studied. Alfalfa seedlings grown on $\mathrm{N}$-free agar slants were inoculated with a mixture of gusA-tagged LU04, LU09, and LU12 and the isogenic parental strains (Table III). As results, an equal number of $\mathrm{Gus}^{+} / \mathrm{Gus}^{-}$nodules was found only in the case of LU09gusA/LU09 inoculation. The LU04gusA and LU12gusA-tagged strains were less competitive in relation to the parental strains but their ability of plant growth promotion was confirmed (Table III). In conclusion, gusA-tagging does not seem to affect substantially the nodule occupation ability under laboratory conditions.

In the next experiment, competitiveness of the six isolates in relation to resident soil rhizobia were investigated under competitive conditions in the soil (experiment 1). The gusA-tagged E. meliloti strains were

Table III

Symbiotic performance and alfalfa nodule occupancy of E. meliloti Gus ${ }^{+}$versus Gus ${ }^{-}$strains assayed under laboratory conditions. Alfalfa plants were inoculated with 1:1 mixture of gusA-tagged and parental, isogenic rhizobia and grown on $\mathrm{N}$-free agar medium slants.

\begin{tabular}{|l|c|c|c|c|}
\hline \multicolumn{1}{|c|}{ Strains } & $\begin{array}{c}\text { Green mass of shoots } \\
(\mathrm{mg})\end{array}$ & $\begin{array}{c}\text { Mass of whole plant } \\
(\mathrm{mg})\end{array}$ & $\begin{array}{c}\text { Number } \\
\text { of nodules }^{\star}\end{array}$ & $\begin{array}{c}\text { Percentage of GUS } \\
\text { GUS }^{-} \text {nodules }\end{array}$ \\
\hline LU04gusA/ LU04 & $76.6 \pm 23.3$ & $117.6 \pm 26.9$ & $12.3 \pm 7.6$ & $35 / 65$ \\
\hline LU09gusA/ LU09 & $81.6 \pm 27.5$ & $129.5 \pm 27.4$ & $12.7 \pm 6.2$ & $53 / 47$ \\
\hline LU12gusA/ LU12 & $87.3 \pm 21.3$ & $126.2 \pm 33.8$ & $10.5 \pm 5.3$ & $39 / 61$ \\
\hline Uninoculated control & $25.6 \pm 9.9$ & $63.6 \pm 20.4$ & 0 & - \\
\hline
\end{tabular}

* Values are mean of 20 plants. \pm standard deviation. 
Table IV

Competitiveness of E. meliloti gusA-tagged isolates assayed on Medicago sativa grown under competitive conditions in the soil

\begin{tabular}{|c|c|c|c|c|}
\hline \multirow{4}{*}{$\begin{array}{c}\text { Ensifer meliloti } \\
\text { gusA - tagged } \\
\text { strains }\end{array}$} & \multicolumn{4}{|c|}{ Gus $^{+} /$Gus $^{-}$nodules* $(\%)$} \\
\hline & \multirow{3}{*}{$\begin{array}{c}\text { Experiment } 1 \\
\text { Seeds soaking with } \\
\sim 10^{8} \text { cells } / \mathrm{ml} / \text { pot }\end{array}$} & \multicolumn{3}{|c|}{ Experiment 2} \\
\hline & & \multicolumn{3}{|c|}{ number of rhizobia / pot } \\
\hline & & $10^{8}$ & $10^{9}$ & $10^{10}$ \\
\hline LU04gusA & $60 / 40$ & $25 / 75$ & $36 / 64$ & $46 / 54$ \\
\hline LU06gusA & $53 / 47$ & $6 / 94$ & $24 / 76$ & 29/71 \\
\hline LU09gusA & $56 / 44$ & $23 / 77$ & $27 / 73$ & $55 / 45$ \\
\hline LU10gusA & $67 / 33$ & $14 / 86$ & $21 / 79$ & $42 / 58$ \\
\hline LU11gusA & $38 / 62$ & $25 / 75$ & $60 / 40$ & $87 / 13$ \\
\hline LU012gusA & $78 / 22$ & $15 / 85$ & $57 / 43$ & $87 / 13$ \\
\hline
\end{tabular}

* In experiment 1 - alfalfa seeds were soaked with respective E. meliloti

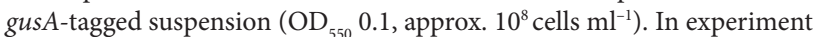
2 - defined numbers of particular rhizobia were added to pot with the soil. Total number of white and blue nodules in each of 20 plants from one pot was estimated and percentages of blue nodules were counted. Values are mean of GUS ${ }^{+}$nodules of 20 plants.

introduced into soil through alfalfa seeds imbibed with rhizobia at a concentration of $\sim 10^{8} \mathrm{ml}^{-1}$ and 6 weeks after inoculation, colonization of nodules by marked and autochthonous rhizobia was examined (Table IV, experiment 1 ). In experiment 1 , the $\mathrm{Gus}^{+}$nodules were detected in the range from $38 \%$ (LU11gusA) to $78 \%$ (LU12gusA) of the total number of nodules. LU12gusA, LU10gusA, and LU04gusA were considered the most competitive in relation to soil resident rhizobia.

In experiment 2 , the competitiveness of individual E. meliloti strains was studied as an effect of an increasing number of rhizobia added to the pots (Table IV, experiment 2). The percentage of $\mathrm{Gus}^{+}$nodules in alfalfa was correlated with the increasing number of rhizobia added to the soil. LU11gusA and LU12gusA were shown to be the most competitive occupying up to $87 \%$ of nodules after inoculation with $10^{10}$ rhizobia per pot. Moreover, LU12 colonized the nodules efficiently in both experiments, giving a high percentage of $\mathrm{GUS}^{+}$nodules irrespective of the method used for seeds inoculation. Similarly to LU12, the competitiveness of LU09gusA (about 55\%) was very similar in both types of seed inoculation; however, it was lower than that of LU12. It was shown that alfalfa inoculation with a high number of bacteria $\left(10^{10} \mathrm{cells} / \mathrm{pot}\right)$ gave comparable results to those obtained with soaking the seeds with a rhizobial suspension containing $c a .10^{8}$ cells; however, from the practical point of view, seed imbibition may be more convenient because it requires a lower total amount of the inoculant (Table IV). Rhizobial competition for nodule occupation studied under competitive conditions once again occurred to be very complex and ambiguous. Overall, among the sampled E. meliloti alfalfa nodule isolates, two strains (LU09 and LU12) proved to be repeatedly effective competitors efficient in symbiotic nitrogen fixation.

Metabolic profiles of the sampled E. meliloti strains. The metabolic properties of rhizobia have enabled them to adapt to the specific, soil and plant tissue environments. The metabolic profiles of the six E. meliloti isolates were studied employing Biolog GN2 microplates containing 96 carbon and energy sources. To simplify the analysis, the substrates in the GN2 microplates were divided into sugars (polysaccharides, oligosaccharides, monosaccharides - comprising $34.4 \%$ of the tested compounds), modified sugar acids, carboxylic acids (29.2\%), amino acids (21.9\%), nitrogen bases and other compounds (15.5\%) (Fig. 4).

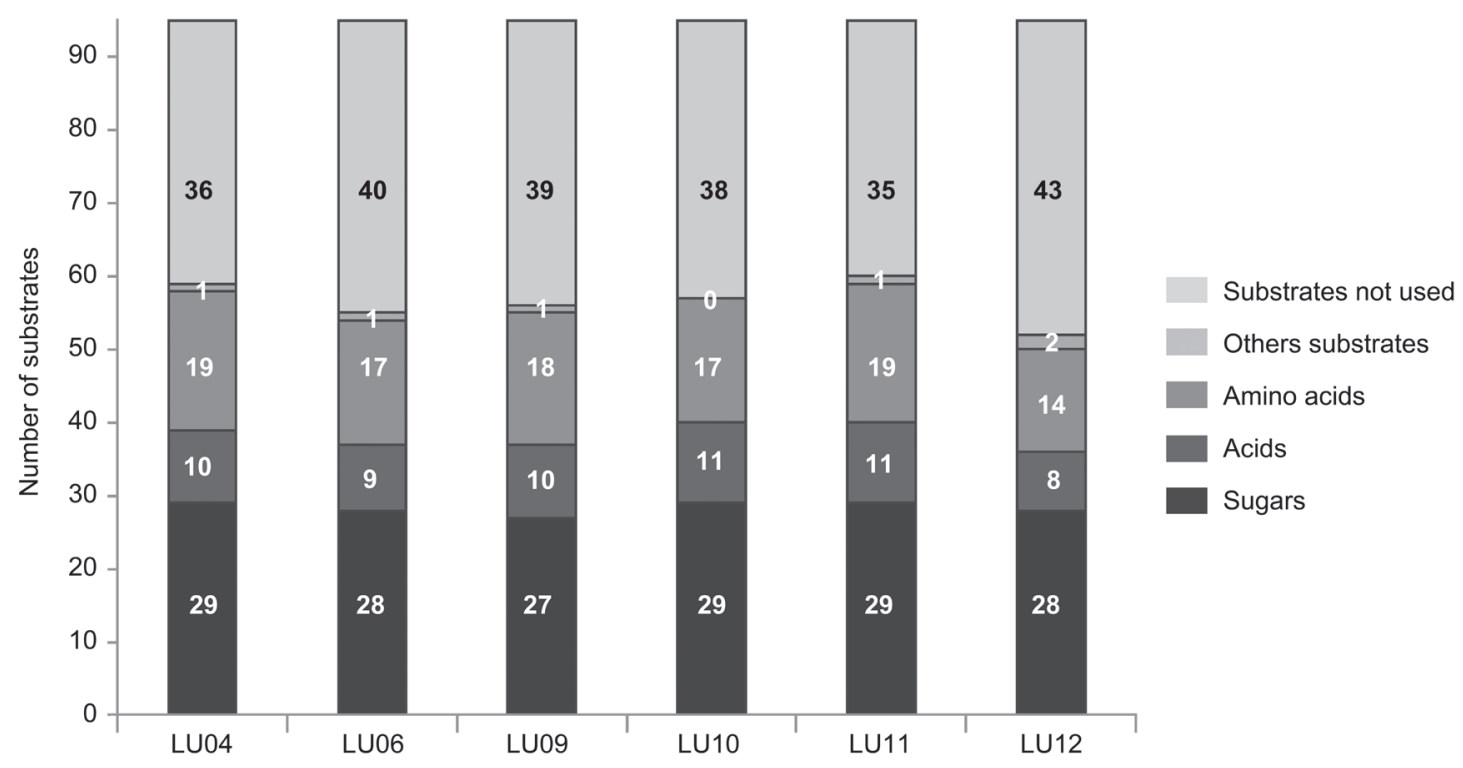

Fig. 4. Metabolic profiles of Ensifer meliloti isolates assayed on Biolog GN2 microplates. The metabolic substrates were divided into 4 groups - sugars, acids, amino acids and other substrates. The number of substrates utilized in each of the groups and number not used substrates 
The assay revealed that the sampled E. meliloti strains have similar capability to use various carbon and energy sources, and the total number of substrates metabolized by individual strains varied from 52 (LU12) to 60 (LU11) (Fig. 4). The differences in using "sugars" refer mainly to glycogen and $\mathrm{N}$-acetyl-D-galactosamine metabolism. In the group of "acids", LU12 did not use $\alpha$ - and $\beta$-hydroxybutyric acids, $\alpha$-keto-butyric, and a-keto-valeric acid. Similarly, LU06, LU09, and LU10 did not use some of the organic acids (Table V). The most noticeable changes in the metabolic profile of the sampled isolates were observed in the group of "amino acid" substrates; in particular, LU12 was defective in using D-alanine, glycyl-L-aspartic acid, L-histidine, and L-threonine. On the other hand, this strain used thymidine, phenylethyl-amine, and D, L-a-glycerol phosphate, which were not metabolized by the other strains. Unexpectedly, the most competitive LU12 strain was able to use the lowest number of compounds compared to other strains.

The selected rhizobia were also investigated for mineral phosphate solubilization and bacteriocin production. These capabilities of rhizobia may be considered as factors affecting survival in the soil and competitiveness. LU10 and LU12, producing $12-13 \mathrm{~mm}$ clear zones around the bacterial colonies, were found to be the most efficient strains in mobilization of inorganic phosphates. The LU11 strain did not solubilize mineral phosphates at all. LU04, LU06, and LU09 formed zones of 6-7 $\mathrm{mm}$ in diameter. Among the six sampled strains, only LU09 was able to produce antimicrobial compounds, which inhibited the growth of bacteriocinsensitive E. meliloti L5.30.

\section{Discussion}

Nodulation competitiveness and efficient nitrogen fixation are two main traits determining the agricultural value of rhizobial strains used as plant inoculants. These traits are independent of each other and remain under the influence of many genetic and environmental factors (Laguerre et al., 2003). Probably, highly efficient and simultaneously competitive strains constitute only a small fraction among numerous rhizobia strains in soil. Nitrogen fixation in agriculture can be improved by inoculation of legume crops with selected more efficient rhizobia, which can outcompete indigenous less effective bacteria. Effective legume inoculants have been sought for years, because most selected strains are not fit for agricultural application due to their low competition abilities or low symbiotic efficiency (Streeter, 1994; Rodríguez-Blanco et al., 2010). Some effort has been made for construction of genetically engineered rhizobia with improved competition capabilities (van
Dillewijn et al., 2001), but the real use of such strains remains controversial. In addition, lowered competitiveness could be a consequence of the presence of other (non-rhizobial) strains affecting the growth of legume microsymbionts or obstacles in proper plantbacteria signal exchange ( $\mathrm{Li}$ and Alexander, 1986; Zhan and Smith, 2002; Laguerre et al., 2012).

In this study, we selected and characterized E. meliloti nodule isolates, which have potential to be used as efficient and competitive inoculants for alfalfa. The autochthonous soil rhizobia, taxonomically identified as closely related to E. meliloti, proved to be considerably diverse in respect to the content of plasmids, which was markedly higher than that reported earlier (Broughton et al., 1987; Hynes and O'Connel, 1990). Despite the diversity in the plasmid content, the BOX- and ERICPCR genomic DNA fingerprints of the selected six isolates were similar in $68-90 \%$. Besides the genomic similarity, in the study of the competitiveness of E. meliloti gusA-tagged strains, considerable diversity in the ability to occupy nodules was noticed. In the two methods used for seed inoculation i.e., seed soaking and seed watering with a suspension of the inoculant, the levels of nodule occupation measured by the number of nodules occupied by the gusA-tagged strains were comparable when large doses of bacteria were applied (Table III). LU12gusA and LU09gusA were reproducibly good competitors in respect to the indigenous rhizobial soil population regardless of the inoculation method and, concomitantly, efficient in $\mathrm{N}_{2}$ fixation.

There is some evidence that the ability to utilize various carbon and energy sources is one of the factors that may influence competitiveness of rhizobia (Baldani et al., 1992; Bringhurst et al. 2001; Ding et al., 2012; Hynes and O'Connel, 1990; Oresnik et al., 1998; Vanderlinde etal., 2014; Wielbo et al., 2007; 2010a; Yost et al., 2004). In the study of the selected E. meliloti strains, we noticed low diversity in the abilities of utilization of carbon and energy sources. The strains utilized on average 56 of 94 (59.6\%) of the tested compounds and the differences between the isolates concerned mainly the utilization of individual substrates from the groups of acids and amino acids (Fig. 4, Table V). These nutrients are the major components of leguminous root exudates and may act as strong chemoattractants for rhizobia (Gaworzewska and Carlile, 1982; Miller et al., 2007).

Amino acids are important compounds in the plantbacteroid exchange of carbon and energy (Lodwig and Poole, 2003). The most metabolically distinct LU12 used the lowest number of acids and amino acids; however, it used thymidine and phenylethyl-amine, and D, L-a-glycerol phosphate, which were not used by the other strains. In addition, LU12 was distinguished by its capability to mobilize inorganic phosphates, which 
Table V

Metabolic profiles of Ensifer sp. isolates assayed on Biolog GN2 microplates.

\begin{tabular}{|c|c|c|c|c|c|c|c|}
\hline $\mathrm{nr}$ & & LU04 & LU06 & LU09 & LU10 & LU11 & LU12 \\
\hline 1 & Water & 0 & 0 & 0 & 0 & 0 & 0 \\
\hline 2 & a-Cyclodextrin & 0 & 0 & 0 & 0 & 0 & 0 \\
\hline 3 & Dextrin & 0 & 0 & 0 & 0 & 0 & 0 \\
\hline 4 & Glycogen & 1 & 0 & 0 & 1 & 1 & 0 \\
\hline 5 & Tween 40 & 0 & 0 & 0 & 0 & 0 & 0 \\
\hline 6 & Tween 80 & 0 & 0 & 0 & 0 & 0 & 0 \\
\hline 7 & N-Acetyl-D-Galactosamine & 1 & 1 & 0 & 0 & 1 & 0 \\
\hline 8 & N-Acetyl-D-Glucosamine & 1 & 1 & 1 & 1 & 1 & 1 \\
\hline 9 & Adonitol & 1 & 1 & 1 & 1 & 1 & 1 \\
\hline 10 & L-Arabinose & 1 & 1 & 1 & 1 & 1 & 1 \\
\hline 11 & D-Arabitol & 1 & 1 & 1 & 1 & 1 & 1 \\
\hline 12 & D-Cellobiose & 1 & 1 & 1 & 1 & 1 & 1 \\
\hline 13 & i-Erythritol & 1 & 1 & 1 & 1 & 1 & 1 \\
\hline 14 & D-Fructose & 1 & 1 & 1 & 1 & 1 & 1 \\
\hline 15 & L-Fucose & 1 & 1 & 1 & 1 & 1 & 1 \\
\hline 16 & D-Galactose & 1 & 1 & 1 & 1 & 1 & 1 \\
\hline 17 & Gentiobiose & 1 & 1 & 1 & 1 & 1 & 1 \\
\hline 18 & a-D-Glucose & 1 & 1 & 1 & 1 & 1 & 1 \\
\hline 19 & m-Inositol & 1 & 1 & 1 & 1 & 1 & 1 \\
\hline 20 & $\alpha$-D-Lactose & 1 & 1 & 1 & 1 & 1 & 1 \\
\hline 21 & Lactulose & 1 & 1 & 1 & 1 & 1 & 1 \\
\hline 22 & Maltose & 1 & 1 & 1 & 1 & 1 & 1 \\
\hline 23 & D-Mannitol & 1 & 1 & 1 & 1 & 1 & 1 \\
\hline 24 & D-Mannose & 1 & 1 & 1 & 1 & 1 & 1 \\
\hline 25 & D-Melibiose & 1 & 1 & 1 & 1 & 1 & 1 \\
\hline 26 & $\beta$-Methyl-D-Glucoside & 1 & 1 & 1 & 1 & 1 & 1 \\
\hline 27 & D-Psicose & 1 & 1 & 1 & 1 & 1 & 1 \\
\hline 28 & D-Raffinose & 1 & 1 & 1 & 1 & 1 & 1 \\
\hline 29 & L-Rhamnose & 1 & 1 & 1 & 1 & 1 & 1 \\
\hline 30 & D-Sorbitol & 1 & 1 & 1 & 1 & 1 & 1 \\
\hline 31 & Sucrose & 1 & 1 & 1 & 1 & 1 & 1 \\
\hline 32 & D-Trehalose & 1 & 1 & 1 & 1 & 1 & 1 \\
\hline 33 & Turanose & 1 & 1 & 1 & 1 & 1 & 1 \\
\hline 34 & Xylitol & 0 & 0 & 0 & 0 & 0 & 0 \\
\hline 35 & Pyruvic Acid Methyl Ester & 1 & 1 & 1 & 1 & 1 & 1 \\
\hline 36 & Succinic Acid Mono-Methyl-Ester & 1 & 1 & 1 & 1 & 1 & 1 \\
\hline 37 & Acetic Acid & 1 & 1 & 1 & 1 & 1 & 1 \\
\hline 38 & Cis-Aconitic Acid & 0 & 0 & 0 & 0 & 0 & 0 \\
\hline 39 & Citric Acid & 0 & 0 & 0 & 0 & 0 & 0 \\
\hline 40 & Formic Acid & 1 & 1 & 1 & 1 & 1 & 1 \\
\hline 41 & D-Galactonic Acid Lactone & 0 & 0 & 0 & 0 & 0 & 0 \\
\hline 42 & D-Galacturonic Acid & 0 & 0 & 0 & 0 & 0 & 0 \\
\hline 43 & D-Gluconic Acid & 0 & 0 & 0 & 0 & 0 & 0 \\
\hline 44 & D-Glucosaminic Acid & 0 & 0 & 0 & 0 & 0 & 0 \\
\hline 45 & D-Glucuronic Acid & 0 & 0 & 0 & 0 & 0 & 0 \\
\hline 46 & a-Hydroxybutyric Acid & 1 & 1 & 1 & 1 & 1 & 0 \\
\hline 47 & $\beta$-Hydroxybutyric Acid & 1 & 1 & 1 & 1 & 1 & 0 \\
\hline 48 & $\gamma$-Hydroxybutyric Acid & 0 & 0 & 0 & 0 & 0 & 0 \\
\hline
\end{tabular}


Table V. Continued

\begin{tabular}{|c|c|c|c|c|c|c|c|}
\hline $\mathrm{nr}$ & & LU04 & LU06 & LU09 & LU10 & LU11 & LU12 \\
\hline 49 & p-Hydroxy Phenylacetic Acid & 0 & 0 & 0 & 0 & 0 & 0 \\
\hline 50 & Itaconic Acid & 0 & 0 & 0 & 0 & 0 & 0 \\
\hline 51 & a-Keto Butyric Acid & 1 & 0 & 1 & 0 & 1 & 0 \\
\hline 52 & a-Keto Glutaric Acid & 0 & 0 & 0 & 0 & 0 & 0 \\
\hline 53 & a-Keto Valeric Acid & 0 & 0 & 0 & 1 & 1 & 0 \\
\hline 54 & D,L-Lactic Acid & 1 & 1 & 1 & 1 & 1 & 1 \\
\hline 55 & Malonic Acid & 0 & 0 & 0 & 0 & 0 & 0 \\
\hline 56 & Propionic Acid & 1 & 1 & 1 & 1 & 1 & 1 \\
\hline 57 & Quinic Acid & 0 & 0 & 0 & 0 & 0 & 0 \\
\hline 58 & D-Saccharic Acid & 0 & 0 & 0 & 0 & 0 & 1 \\
\hline 59 & Sebacic Acid & 0 & 0 & 0 & 0 & 0 & 0 \\
\hline 60 & Succinic Acid & 1 & 1 & 1 & 1 & 1 & 1 \\
\hline 61 & Bromosuccinic Acid & 1 & 1 & 1 & 1 & 1 & 1 \\
\hline 62 & Succinamic Acid & 0 & 0 & 0 & 0 & 0 & 0 \\
\hline 63 & Glucuronamide & 0 & 0 & 0 & 1 & 0 & 0 \\
\hline 64 & L-Alaninamide & 1 & 1 & 1 & 1 & 1 & 1 \\
\hline 65 & D-Alanine & 1 & 1 & 1 & 1 & 1 & 0 \\
\hline 66 & L-Alanine & 1 & 1 & 1 & 1 & 1 & 1 \\
\hline 67 & L-Alanyl-glycine & 1 & 1 & 1 & 1 & 1 & 1 \\
\hline 68 & L-Asparagine & 1 & 1 & 1 & 1 & 1 & 1 \\
\hline 69 & L-Aspartic Acid & 1 & 1 & 1 & 1 & 1 & 1 \\
\hline 70 & L-Glutamic Acid & 1 & 1 & 1 & 1 & 1 & 1 \\
\hline 71 & Glycyl-L-Aspartic Acid & 1 & 0 & 0 & 0 & 1 & 0 \\
\hline 72 & Glycyl-L-glutamic Acid & 1 & 1 & 1 & 1 & 1 & 1 \\
\hline 73 & L-Histidine & 1 & 1 & 1 & 0 & 1 & 0 \\
\hline 74 & Hydroxy-L-Proline & 1 & 1 & 1 & 1 & 1 & 1 \\
\hline 75 & L-Leucine & 1 & 1 & 1 & 1 & 1 & 1 \\
\hline 76 & L-Ornithine & 1 & 1 & 1 & 1 & 1 & 1 \\
\hline 77 & L-Phenylalanine & 0 & 0 & 0 & 0 & 0 & 0 \\
\hline 78 & L-Proline & 1 & 1 & 1 & 1 & 1 & 1 \\
\hline 79 & L-Pyroglutamic Acid & 0 & 0 & 0 & 0 & 0 & 0 \\
\hline 80 & D-Serine & 0 & 0 & 0 & 0 & 0 & 0 \\
\hline 81 & L-Serine & 1 & 1 & 1 & 1 & 1 & 1 \\
\hline 82 & L-Threonine & 1 & 1 & 1 & 0 & 1 & 0 \\
\hline 83 & D,L-Carnitine & 1 & 0 & 1 & 1 & 1 & 1 \\
\hline 84 & $\gamma$-Amino Butyric Acid & 1 & 1 & 1 & 1 & 1 & 0 \\
\hline 85 & Urocanic Acid & 1 & 1 & 1 & 1 & 1 & 1 \\
\hline 86 & Inosine & 0 & 0 & 1 & 0 & 0 & 0 \\
\hline 87 & Uridine & 1 & 1 & 0 & 0 & 1 & 0 \\
\hline 88 & Thymidine & 0 & 0 & 0 & 0 & 0 & 1 \\
\hline 89 & Phenylethyl-amine & 0 & 0 & 0 & 0 & 0 & 1 \\
\hline 90 & Putrescine & 0 & 0 & 0 & 0 & 0 & 0 \\
\hline 91 & 2-Aminoethanol & 0 & 0 & 0 & 0 & 0 & 0 \\
\hline 92 & 2,3-Butanediol & 0 & 0 & 0 & 0 & 0 & 0 \\
\hline 93 & Glycerol & 1 & 1 & 1 & 1 & 1 & 1 \\
\hline 94 & D,L-a-Glycerol Phosphate & 0 & 0 & 0 & 0 & 0 & 1 \\
\hline 95 & a-D-Glucose-1-Phosphate & 0 & 0 & 0 & 0 & 0 & 0 \\
\hline 96 & D-Glucose-6-Phosphate & 0 & 0 & 0 & 0 & 0 & 0 \\
\hline
\end{tabular}

0 - negative result; 1 - positive result. 
is an important trait influencing bacterial persistence in soil and plant growth promotion (Rodriguez and Fraga, 1999). Also, LU09 was the only one of the six sampled strains that was able to produce antimicrobial compounds inhibiting the growth of the bacteriocin-sensitive E. meliloti L5.30. Both capabilities could enhance their persistence in soil. In the previous study of Rhizobium leguminosarum bv. trifolii population, it was evidenced that rhizobia with specialized metabolism rarely occurred in the soil but they were more effective in symbiosis (Wielbo et al., 2010a). It may be speculated that the capability to utilize substrates that are more difficult to metabolize is the discriminatory trait for competitive and uncompetitive strains, and specific adjustment of rhizobial metabolism to the plant exudate content is one of the most important elements of competitiveness. Overall, by gradual selection of the E. meliloti isolates, LU12 and LU09 were selected as efficient and reproducibly competitive strains in symbiosis with $M$. sativa, which will be further examined in order to develop alfalfa inoculants.

\section{Acknowledgements}

The present study was conducted by the research fund of M. Curie-Skłodowska University in 2013.

\section{Literature}

Aoki S., S. Nakata, T. Kajita and M. Ito. 2010. Genotypic and phenotypic diversity of rhizobia isolated from Lathyrus japonicus indigenous to Japan. Syst. Appl. Microbiol. 33: 383-397.

Baldani J.I., R.W. Weaver, M.F. Hynes and B.D. Eardly. 1992. Utilization of carbon substrates, electrophoretic enzyme patterns, and symbiotic performance of plasmid-cured clover rhizobia. Appl. Environ. Microbiol. 58: 2308-2314.

Barnett M.J., R.F. Fisher, T. Jones, C. Komp, A.P. Abola, F. BarloyHubler, L. Bowser, D. Capela, F. Galibert, J. Gouzy and others. 2001. Nucleotide sequence and predicted functions of the entire Sinorhizobium meliloti pSymA megaplasmid. Proc. Natl. Acad. Sci. U.S.A. 98: 9883-9888.

Bringhurst R.M., Z.G. Cardon and D.J. Gage. 2001. Galactosides in the rhizosphere: utilization by Sinorhizobium meliloti and development of a biosensor. Proc. Natl. Acad. Sci. USA 98: 4540-4545. Brockwell J. 1982. Plant-infection counts of rhizobia in soils, pp. 41-58. In: Vincent JM (ed.), Nitrogen fixation in legumes. Academic Press Australia, Sydney 1982.

Brockwell J., P.J. Bottomley and J.E. Thies. 1995. Manipulation of rhizobia microflora for improving legume productivity and soil fertility: a critical assessment. Plant Soil 174: 143-180.

Bromfield E.S.P., J.T. Tambong, S. Cloutier, D. Prévost, G. Laguerre, P. van Berkum, T.V. Tran Thi, R. Assabgui and L.R. Barran. 2010. Ensifer, Phyllobacterium and Rhizobium species occupy nodules of Medicago sativa (alfalfa) and Melilotus alba (sweet clover) grown at a Canadian site without a history of cultivation. Microbiology 156: 505-520.

Broughton W.J., N. Heycke, U. Priefer, G.M. Schneider and J. Stanley. 1987. Ecological genetics of Rhizobium meliloti: diversity and competitive dominance. FEMS Microbiol. Lett. 40: 245-249.
Calvert H.E., M.K. Pence, M. Pierce, N.S.A. Malik and W.D. Bauer. 1984. Anatomical analysis of the development and distribution of Rhizobium infections in soybean roots. Can. J. Bot. 62: 2375-2384. Depret G. and G. Laguerre. 2008. Plant phenology and genetic variability on root and nodule development strongly influence genetic structuring of Rhizobium leguminosarum biovar viciae populations nodulating pea. New Phytol. 179: 224-235.

Ding H., C.B. Yip, B.A. Geddes, I.J. Oresnik and M.F. Hynes. 2012. Glycerol utilization by Rhizobium leguminosarum requires an $\mathrm{ABC}$ transporter and affects competition for nodulation. Microbiology 58: 1369-1378.

Eckhardt T. 1978. A rapid method for the identification of plasmid deoxyribonucleic acid in bacteria. Plasmid 1: 584-588.

Felsenstein J. 1985. Phylogenies and the comparative method. American Naturalist 125: 1-15.

Gaunt M.W., S.L. Turner, L. Rigottier-Gois, S.A. Lloyd-Macgilps and J.P.W. Young. 2001. Phylogenies of $a t p D$ and $r e c A$ support the small subunit rRNA-based classification of rhizobia. Intern. J. Syst. Evol. Microbiol. 51: 2037-2048.

Gaworzewska E.T. and M.J. Carlile. 1982. Positive chemotaxis of Rhizobium leguminosarum and other bacteria towards root exudates from legumes and other plants. J. Gen. Microbiol. 128: 1179-1188. Herridge D.F., M.B. Peoples and R.M. Boddey. 2008. Global inputs of biological nitrogen fixation in agricultural systems. Plant Soil 311: 1-18.

Hynes M.F. and M.P. O'Connel. 1990. Host plant effect on competition among strains of Rhizobium leguminosarum. Can. J. Microbiol. 36: 864-869.

Jones K.M., H. Kobayashi, B.W. Davies, M.E. Tagaand, G.C. Walker. 2007. How rhizobial symbionts invade plants: the Sinorhizobium-Medicago model. Nat. Rev. Microbiol. 5: 619-633.

Kimura M. 1980. A simple method for estimating evolutionary rates of base substitutions through comparative studies of nucleotide sequences. J. Mol. Evol. 16: 111-120.

Laguerre G., K. Heulin-Gotty, B. Brunel, A. Klonowska, A. Le Quéré, P. Tillard, Y. Prin, J. Cleyet-Marel and M. Lepetit. 2012. Local and systemic N signaling are involved in Medicago truncatula preference for the most efficient Sinorhizobium symbiotic partners. New Phytologist 195: 437-449.

Laguerre G., P. Louvrier, M.R. Allard and N. Amarger. 2003. Compatibility of rhizobial genotypes within natural populations of Rhizobium leguminosarum biovar viciae for nodulation of host legumes. Appl. Environ. Microbiol. 69: 2276-2283.

Laguerre G., P. Mavingui, M.R. Allard, M.P. Charnay, P. Louvrier, S.I. Mazurier, L. Rigottier-Gois and N. Amarger. 1996. Typing of rhizobia by PCR DNA fingerprinting and PCR-restriction fragment length polymorphism analysis of chromosomal and symbiotic gene regions: application to Rhizobium leguminosarum and its different biovars. Appl. Environ. Microbiol. 62: 2029-2036.

Li D.M. and M. Alexander. 1986. Bacterial growth rates and competition affect nodulation and root colonization by Rhizobium meliloti. Appl. Environ. Microbiol. 52: 807-811.

Lodwig E. and P. Poole. 2003. Metabolism of Rhizobium bacteroids. Critic. Rev. Plant Sci. 22, 37-78.

Louws F.J., D.W. Fulbright and C.T. Stephens. 1994. Specific genomic fingerprints of phytopathogenic Xanthomonas and Pseudomonas pathovars and strains generated with repetitive sequences and PCR. Appl. Environ. Microbiol. 60: 2286-2295.

Martinez-Romero E. and J. Caballero-Mellado. 1996. Rhizobium phylogenies and bacterial genetic diversity. Crit. Rev. Plant Sci. 15: 113-140.

Martyniuk S., J. Oroń and M. Martyniuk. 2005. Diversity and numbers of root-nodule bacteria (rhizobia) in Polish soils. Acta Soc. Bot. Polon. 74: 83-86. 
Martyniuk S., A. Woźniakowska, M. Martyniuk and J. Oroń. 2000. A new sand pouch-plant infection technique for enumeration of rhizobia in soil. Acta Soc. Bot. Polon. 69: 257-261.

Masson-Boivin C., E. Giraud, X. Perret and J. Batut. 2009. Establishing nitrogen-fixing symbiosis with legumes: how many rhizobium recipes? Trends Microbiol. 17: 458-466.

Mathesius U., J.J. Weinmann, B.G. Rolfe and M.A. Djordjevic. 2000. Rhizobia can induce nodules in white clover by "hijacking" mature cortical cells activated during lateral root development. Mol. Plant Microbe Interact. 13: 170-182.

Miller L.D., C.K. Yost, M.F. Hynes and G. Alexandre. 2007. The major chemotaxis gene cluster of Rhizobium leguminosarum bv. viciae is essential for competitive nodulation. Mol. Microbiol. 63: 348-362.

Oresnik I.J., L.A. Pacarynuk, S.H.P. O'Brien, C. Yost and M.F. Hynes. 1998. Plasmid-encoded catabolic genes in Rhizobium leguminosarum bv. trifolii: evidence for a plant-inducible rhamnose locus involved in competition for nodulation. Mol. Plant Microbe Interact. 11: 1175-1185.

Palacios R. and W.E. Newton. 2005. Genomes and genomics of nitrogen-fixing organisms. Springer, Dordrecht.

Perret X., C. Staehelin and W. Broughton. 2000. Molecular basis of symbiotic promiscuity. Microbiol. Mol. Biol. Rev. 64: 180-201.

Pitcher D.G., N.A. Saunders and R.J. Owen. 1989. Rapid extraction of bacterial genomic DNA with guanidine thiocyanate. Lett Appl. Microbiol. 8: 151-156.

Rodriguez H. and R. Fraga. 1999. Phosphate solubilizing bacteria and their role in plant growth promotion. Biotech. Adv. 17: 319-339. Rodríguez-Blanco A., M. Sicardi and L. Frioni. 2010. Competition for nodule occupancy between introduced and native strains of Rhizobium leguminosarum biovar trifolii. Biol. Fertil. Soils 46: 419-425 Silva C., F.L. Kan and E. Martinez-Romero. 2007. Population genetic structure of Sinorhizobium meliloti and S. medicae isolated from nodules of Medicago spp. in Mexico. FEMS Microbiol. Ecol. 60: $477-489$.

Simms E.L. and D.L. Taylor. 2002. Partner choice in nitrogenfixation mutualism of legumes and rhizobia. Integ. Comp. Biol. 42 : 369-380.

Streeter J.G. 1994. Failure of inoculant rhizobia to overcome the dominance of indigenous strains for nodule formation. Can. J. Microbiol. 40: 513-522.

Tamura K., D. Peterson, N. Peterson, G. Stecher, M. Nei and S. Kumar. 2011. MEGA5: Molecular evolutionary genetics analysis using maximum likelihood, evolutionary distance, and maximum parsimony methods. Mol. Biol. Evol. 28: 2731-2739.

Triplett E.W. and M.J. Sadowsky. 1992. Genetics of competition for nodulation of legumes. Ann. Rev. Microbiol. 40: 399-428.
Van Dillewijn P., M.J. Soto, P.J. Villadas and N. Toro. 2001. Construction and environmental release of a Sinorhizobium meliloti strain genetically modified to be more competitive for alfalfa nodulation. Appl. Environ. Microbiol. 67: 3860-3865.

Vanderlinde E.M., M.F. Hynes and C.K. Yost. 2014. Homoserine catabolism by Rhizobium leguminosarum bv. viciae 3841 requires a plasmid-borne gene cluster that also affects competitiveness for nodulation. Environ. Microbiol. 16: 205-217.

Versalovic J., T. Koeuth and R.J. Lupski. 1991. Distribution of repetitive DNA sequences in eubacteria and application to fingerprinting of bacterial genomes. Nucleic Acids Res. 9: 6823-6831.

Vincent J.M. 1970. A manual for the practical study of the rootnodule bacteria. IBP handbook no.15. Blackwell Scientific Publishers, Oxford, England.

Weisburg W.G., S.M. Barns, D.A. Pelletier and D.J. Lane. 1991. $16 \mathrm{~S}$ ribosomal DNA amplification for phylogenetic study. J. Bacteriol. 173: 697-703.

Wielbo J., M. Marek-Kozaczuk, A. Kubik-Komar and A. Skorupska. 2007. Increased metabolic potential of Rhizobium spp. is associated with bacterial competitiveness. Can. J. Microbiol. 53: 957-967. Wielbo J., M. Marek-Kozaczuk, A. Mazur, A. Kubik-Komar and A. Skorupska. 2010a. Genetic and metabolic divergence within a Rhizobium leguminosarum bv. trifolii population recovered from clover nodules. Appl. Environ. Microbiol. 76: 4593-4600.

Wielbo J., J. Kuske, M. Marek-Kozaczuk and A. Skorupska. 2010b. The competition between Rhizobium leguminosarum bv. viciae strains progresses until late stages of symbiosis. Plant Soil 337: 125-135.

Wielbo J. and A. Skorupska. 2001. Construction of improved vectors and cassettes containing gusA and antibiotic resistance genes for studies of transcriptional activity and bacterial localization. J. Microbiol. Methods 45: 197-205.

Wilson K.J., A. Sessitsch, J.C. Corbo, K.E. Giller, A.D. Akkermans and R.A. Jefferson. 1995. $\beta$-Glucuronidase (GUS) transposons for ecological and genetic studies of rhizobia and other gram-negative bacteria. Microbiology 141: 1691-705.

Young J.P., L.C. Crossman, A.W. Johnston, N.R. Thomson, Z.F. Ghazoui, K.H. Hull, M. Wexler, A.R. Curson, J.D. Todd, P.S. Poole and others. 2006. The genome of Rhizobium leguminosarum has recognizable core and accessory components, Genome Biol. 7: R34.

Yost C.K., K.L. Del Bel, J. Quandt and M.F. Hynes. 2004. Rhizobium leguminosarum methyl-accepting chemotaxis protein genes are down-regulated in the pea nodule. Arch. Microbiol. 182: 505-513. Zhan F. and D.L. Smith. 2002. Interorganismal signaling in suboptimum environments: the legume-rhizobia symbiosis. Adv. Agronom. 76: 125-161. 